\title{
A cidade de Porto Alegre e as águas do Guaíba: uma história de "encontros" e "desencontros"
}

The city of Porto Alegre and the waters of Lake Guaíba: a history of "closeness" and "distancing"

Antônio João Dias Prestes*

Fabiano Quadros Rückert**

\begin{abstract}
Resumo
O objetivo deste artigo consiste em produzir uma reflexão sobre as relações entre a cidade de Porto Alegre, capital do Rio Grande do Sul, e as águas do Guaíba. Localizado nas margens do lago Guaíba, o sítio urbano porto-alegrense ganhou forma influenciado pelas águas desse manancial que sofreu diferentes tipos de intervenções humanas a partir do desembarque dos primeiros açorianos na região. Partindo da premissa de que as relações entre a cidade de Porto Alegre e as águas do Guaíba foram construídas articulando interesses políticos e econômicos, saberes técnicos e elementos naturais, a primeira parte do artigo aborda o processo de poluição do lago Guaíba; e a segunda parte destaca as iniciativas para sua despoluição e recuperação ambiental, encaminhadas pelo poder público e pela sociedade em diferentes momentos históricos.
\end{abstract}

Palavras-chaves: Porto Alegre; Poluição hídrica; Lago Guaíba; Despoluição.

\begin{abstract}
This paper aims to bring thoughts on the relations between the city of Porto Alegre, capital of the State of Rio Grande do Sul, and the waters of Lake Guaíba. Located by the lake's shore, the urban site of Porto Alegre has been shaped under the influence of this huge water source, which suffered from many human interventions, since the arrival of the first Azorean immigrants in the region. Taking in account that the relationship between the city and the waters of Guaíba had been building by the articulation of political and economic interests, technical knowledge and nature, the paper is divided in two parts. The first one deals with the process of pollution of the Lake Guaíba, while the second focuses on the efforts for its depollution and environmental recovery that has been conducted by public powers and the local society at different historical moments.
\end{abstract}

Keywords: Porto Alegre; Water pollution; Lake Guaíba; Depollution.

\section{Introdução}

O passado da cidade de Porto Alegre contempla uma série de outras histórias. Essas histórias foram escritas em diferentes momentos e com diferentes finalidades. Uma parte do passado da capital do Rio Grande do Sul foi registrada nos textos de cronistas, viajantes e memorialistas, os quais escreveram suas percepções sobre as

\footnotetext{
* Mestre em História pela Universidade Federal do Rio Grande do Sul (UFRGS).

** Doutor em História pela Universidade do Vale do Rio dos Sinos (UNISINOS). Professor da Universidade Federal de Mato Grosso do Sul (UFMS).
}

Recebido em setembro de 2016 | Aprovado em março de 2017. 
mudanças no sítio urbano e sobre o cotidiano da população. Outra parte foi pesquisada por historiadores, arqueólogos, geógrafos, sociólogos, arquitetos e antropólogos interessados no fenômeno da urbanização e nas suas múltiplas interpretações.

A leitura da história de uma cidade não pode desconsiderar a existência de espaços diferenciados dentro do território urbano. A diferenciação dos espaços dentro de uma determinada cidade é produto de desigualdades econômicas inerentes ao sistema capitalista. Ela também é produto de intervenções técnicas necessárias para o funcionamento da urbe - obras viárias, redes de saneamento, etc. - e de valores culturais e simbólicos atribuídos a determinados locais ao longo do processo histórico. No caso específico de Porto Alegre, locais como o Mercado Público, o cais do porto, a Igreja da Matriz, a Santa Casa de Misericórdia, a antiga Casa de Correção, a Usina do Gasômetro, o Teatro São Pedro, o Palácio Piratini e a Rua da Praia são "espaços de referências" para a história e para a identidade da cidade.

Sem desconsiderarmos a historicidade desses "espaços de referências" para a construção e funcionamento da cidade de Porto Alegre, pretendemos destacar, neste artigo, as interações entre a sociedade porto-alegrense e as águas do Guaíba. Na perspectiva que orienta o artigo, a importância do Guaíba não reside no valor estético ou simbólico que ele possui e, sim, na interação entre as suas águas e o metabolismo urbano $^{1}$ de Porto Alegre. Desse modo, propomos apresentar uma narrativa histórica com ênfase no uso das águas do Guaíba no descarte dos resíduos - lixo, esgoto e resíduos industriais - e no abastecimento da população porto-alegrense. Para assegurar a viabilidade da proposta, articulamos diferentes tipos de fontes documentais que registram o processo de poluição do Guaíba e as reações do poder público e da sociedade civil, diante do problema da poluição hídrica configurado na capital sul riograndense.

\section{Um breve histórico sobre a poluição das águas do Guaíba}

A história da poluição das águas do Guaíba poderia ser chamada de uma "história sem fim", na medida em que a contaminação desse manancial não foi

\footnotetext{
${ }^{1}$ Segundo o geógrafo Aziz Ab'saber (1995, p. 11), a expressão metabolismo urbano contempla "todos os processos de saneamento básico, dotados de tecnicidade específica". O mesmo autor afirma que "o metabolismo dos grandes centros urbanos se completa por uma série de diferentes tipos de descargas, relacionadas a processos biológicos, atividades industriais e comerciais, circulação de veículos e resíduos de todos os tipos. Tudo que entrou e transitou através de fluxos complexos, terá de sair sob forma de materiais secundários, profundamente modificados pela metabolização" (AB'SABER, 1995, p. 13-14).
} 
interrompida. E, considerando a alta densidade demográfica na Região Metropolitana de Porto Alegre ${ }^{2}$ e a complexidade dos problemas socioambientais no rio dos Sinos e no rio Gravataí - dois dos principais afluentes do Guaíba - as perspectivas para contenção da poluição hídrica na Bacia Hidrográfica do Guaíba não são boas.

O ritmo do processo de poluição do Guaíba foi intensificado na segunda metade do século $\mathrm{XX}$, mas as origens desse processo encontram-se no século XIX, período em que a capital gaúcha defrontou-se com os problemas decorrentes da urbanização. Para explorar os primórdios dessa experiência de "desencontro" entre a cidade de Porto Alegre e as águas do Guaíba, podemos recorrer aos estudos de Fernanda Tocchetto, Vladimir Ferreira de Ávila, Fabiano Quadros Rückert e Antônio João Dias Prestes, dentre outros.

Fernanda Tocchetto apoiou-se em pesquisas de Arqueologia Urbana para interpretar as práticas de descarte do lixo doméstico na Porto Alegre oitocentista (TOCCHETTO, 2010). Com base em escavações realizadas em diferentes sítios da capital sul rio-grandense, ${ }^{3}$ a autora constatou que, no começo do século XIX, o uso das ruas, quintais e terrenos baldios para o despejo do lixo era parte do cotidiano portoalegrense. Segundo Toccheto, "as lixeiras coletivas formadas com depósitos cotidianos" na antiga orla do Guaíba foram aterradas pela municipalidade porto-alegrense no decorrer do século XIX. Com a prática do aterramento, o poder público atacava focos de insalubridade e, ao mesmo tempo, criava novas áreas para a expansão das atividades urbanas ${ }^{4}$.

Em 1820, antes do aterramento das "lixeiras coletivas" criadas na orla antiga do Guaíba, as condições sanitárias de Porto Alegre provocaram uma impressão negativa no viajante francês Saint'Hilaire.

\footnotetext{
${ }^{2}$ A Região Metropolitana de Porto Alegre - RMPA - é a área mais densamente povoada do Rio Grande do Sul concentrando mais de 4 milhões de habitantes - 37,7\% da população total do Estado. Dela fazem parte 9 dos 18 municípios do RS com mais de 100 mil habitantes. A densidade demográfica média da região é de $389,7 \mathrm{hab} / \mathrm{km}^{2}$.

${ }^{3}$ As escavações arqueológicas que subsidiaram a pesquisa de Fernanda Toccheto foram realizadas nos seguintes locais de Porto Alegre: (1) Chácara da Figueira, situado no Morro Santana; (2) Solar Lopo Gonçalves, localizado nos arrabaldes de Porto Alegre; (3) A Casa da Riachuelo, localizado na região central de Porto Alegre, e por fim, (4) o Solar da Travessa Paraíso, localizado no Menino Deus, Morro Santa Teresa.

4 Tocchetto (2010, p. 259-260) afirma que os aterramentos realizados pela municipalidade portoalegrense na antiga orla do Guaíba possibilitaram a criação da Doca das Frutas (década de 1840), a criação da Praça da Harmonia (década de 1850), a construção do novo Mercado Público, a criação da segunda Doca (década de 1870) e a instalação da Praça das Carretas.
} 
Poucas casas possuem jardins e muitas não têm sequer quintal; daí um grave inconveniente de atirarem à rua todo o lixo, tornando-as imundas. As encruzilhadas, os terrenos baldios e, principalmente, as margens da lagoa são entulhadas de sujeira; os habitantes só bebem água da lagoa e, continuamente, vêem-se negros encher seus cântaros no mesmo lugar em que outros acabam de lavar as mais emporcalhadas vasilhas. (SAINT'HILAIRE, 2002, p. 46).

As observações feitas pelo francês Saint'Hilaire são um interessante registro dos problemas higiênicos enfrentados por um núcleo urbano que possuía, na época, cerca de 10.000 a 12.000 habitantes. Na mesma citação, o Guaíba - chamado pelo viajante de "lagoa" - aparece como um local de descarte do lixo e, ao mesmo tempo, como fonte para o abastecimento de água.

O uso do Guaíba para descarte do lixo doméstico coexistiu com o seu uso para descarte das "materias fecaes". No período imperial, a definição dos locais e horários para despejo dos cubos com "materias fecaes" era uma das responsabilidades da Câmara Municipal de Porto Alegre. E, conforme demonstram os estudos de Ávila (2010), Rückert (2014) e Huyer (2015), a municipalidade porto-alegrense enfrentou dificuldades para controlar a prática dos despejos.

Pesquisando as correspondências e as Atas da Câmara Municipal de Porto Alegre, no período imperial, Ávila constatou que, além de definir os locais em que os despejos deveriam ser realizados, a municipalidade usou as Posturas Municipais para coibir práticas anti-higiênicas e ocupou-se também da construção de trapiches de madeira para assegurar que os despejos ocorressem "sempre dentro da água", ou seja, sempre dentro do Guaíba (ÁVILA, 2010). A recorrência do tema dos despejos fecais nas Atas e correspondências da Câmara pode ser interpretada como uma preocupação das autoridades com a salubridade do espaço urbano e, ao mesmo tempo, pode ser interpretada como um indicativo de que as determinações fixadas nas Posturas Municipais não estavam sendo respeitadas por todos os membros da sociedade portoalegrense $^{5}$. Acreditamos que as duas interpretações são compatíveis e se complementam.

\footnotetext{
${ }^{5}$ Sobre esse aspecto, é importante ressaltar que a documentação consultada por Ávila não nos permite afirmar se a punição por descumprimento das Posturas Municipais era um procedimento comum na Porto Alegre Imperial. Sabemos que a legislação fixava multas para as práticas anti-higiênicas e que havia um serviço de fiscalização sob responsabilidade da municipalidade. Sabemos também que a imprensa portoalegrense do século XIX publicou diversos textos criticando práticas anti-higiênicas e advertindo para a necessidade de cumprimento das Posturas (WEBER, 2012; RÜCKERT, 2014; 2015); no entanto, pouco sabemos sobre a punição dos infratores ou sobre o perfil social destes sujeitos.
} 
A preocupação com o destino das "materias fecaes" era parte da política sanitária no final do século XIX. Naquele contexto, a teoria da transmissão dos miasmas coexistia com a emergente teoria da transmissão hídrica das doenças. As duas teorias divergiam nas suas interpretações sobre o contágio, mas concordavam com a necessidade de afastar as "materias fecaes" do centro urbano, neutralizando potenciais focos de doenças. No caso específico de Porto Alegre, essa necessidade influenciou na decisão da municipalidade pela construção da Estrada de Ferro do Riacho. Atendendo ao parecer de uma Comissão Médica, em 1893 a Intendência decidiu construir uma ferrovia para transportar os cubos do Asseio Público até a Ponta do Dionísio. Depois de superar problemas técnicos, jurídicos e financeiros para executar as obras, a Intendência modificou o percurso da ferrovia e escolheu a Ponta do Mello como local para despejo e lavagem dos cubos do Asseio Público (HUYER, 2015).

A história da criação da Ferrovia do Riacho pode ser narrada a partir de duas perspectivas: sob o ponto de vista sanitário, havia a intenção de afastar as "materias fecaes" recolhidas pelo serviço do Asseio Público da área central de Porto Alegre; e sob o ponto de vista do planejamento urbano, havia uma expectativa de qualificar o transporte entre a Zona Sul e o centro de Porto Alegre. Inicialmente, a preocupação sanitária foi a mais destacada nos documentos da Intendência, a qual planejou e executou a obra. No entanto, nas primeiras décadas do século XX, a Ferrovia do Riacho tornou-se um elemento importante no processo de expansão da cidade.

Percorrendo a orla do Guaíba, e seguindo um trajeto que começava na antiga Ponte do Riacho (atual Ponte dos Açorianos) e terminava na Ponta do Melo, a Ferrovia do Riacho criou uma nova rota de ligação entre o centro de Porto Alegre e os atuais bairros Tristeza, Ipanema e Assumpção; posteriormente, em 1925, um ramal foi estendido até a Vila Nova. Usada para transportar os cubos do Asseio Público para longe do centro e, ao mesmo tempo, usada para transporte de passageiros e cargas, a Ferrovia do Riacho contribuiu para a valorização comercial das terras situadas na zona sul da cidade, possibilitando a criação de novos loteamentos residenciais e fomentando os investimentos na urbanização dos atuais bairros Cristal, Tristeza, Assumpção, Ipanema e Vila Nova ${ }^{6}$.

\footnotetext{
${ }^{6}$ Cabe ressaltar que a conexão entre a Ferrovia do Riacho e a Vila Nova foi inaugurada em 1926, quando foi concluído o ramal ferroviário que tinha como ponto inicial a Estação Ildefonso Pinto. (MACHADO, 2010, p. 79-80).
} 
A importância da Ferrovia do Riacho para a expansão da Zona Sul é reconhecida por diversos autores, dentre os quais podemos citar André Huyer e Janete da Rocha Machado. Trabalhando com a perspectiva da memória, Machado destacou o interesse dos porto-alegrenses, que viveram nas primeiras décadas do século $\mathrm{XX}$, pelos banhos nas praias da Zona Sul e explorou textos de memorialistas como Walter Spalding, Augusto Meyer e Roberto Pellin (MACHADO, 2010). Huyer, por sua vez, pesquisando nos Relatórios da Intendência, explorou as relações entre a Ferrovia do Riacho, a criação de balneários e o loteamento de áreas localizadas nas margens do Guaíba (HUYER, 2015).

A criação dos balneários na Zona Sul de Porto Alegre, ocorrida nos anos 20 e 30, nos permite afirmar que a Ferrovia do Riacho foi o caminho de um agradável “encontro" entre a população porto-alegrense e as águas do Guaíba. No entanto, esse mesmo caminho era usado para afastar os dejetos fecais do centro da capital. Consequentemente, o despejo dos cubos do Asseio Público na Ponta do Melo pode ser interpretado como uma experiência de "desencontro" entre Porto Alegre e as águas do Guaíba.

Explorando o problema do descarte das "materias fecaes" no jornal A Federação, Rückert destacou a participação dos médicos e engenheiros nas discussões sobre a contaminação das águas do Guaíba (RÜCKERT, 2014). As discussões ganharam intensidade na década de 1880; no entanto, a relação entre a poluição das águas do Guaíba e a saúde da população porto-alegrense foi percebida ainda em 1853, pelo Dr. Ubatuba, então Presidente da Comissão de Higiene da Província ${ }^{7}$. Diante do elevado número de óbitos por doenças intestinais, constatado no Mapa Necrológico elaborado pela Comissão de Higiene no respectivo ano, o Dr. Ubatuba atribuiu o fato ao problema da "falta de água potável", à "falta da Polícia Médica" e ao "abuso dos purgantes" (WITTER, 2007, p. 61-62).

A necessidade de evitar o consumo das águas poluídas do Guaíba foi um dos motivos da criação da Companhia Hydráulica Porto-Alegrense, empresa que em 1861 recebeu a concessão para explorar o abastecimento de água na capital do Rio Grande do Sul. Seguindo as determinações previstas no contrato de concessão, a Companhia investiu na captação de água nas nascentes do Arroio do Sabão, atualmente

\footnotetext{
${ }^{7}$ A documentação da Comissão de Higiene da Província foi pesquisada por Nikelen Acosta Witter, na Tese intitulada Males e epidemias: Sofredores, governantes e curadores no sul do Brasil, Rio Grande do Sul, século XIX. (WITTER, 2007). O foco principal da pesquisa da autora foi a epidemia de Cólera que atingiu a capital do Rio Grande do Sul em 1855
} 
conhecido como Arroio Dilúvio (RÜCKERT, 2014; 2015). A preferência da empresa pela captação em um local distante do centro urbano é compreensível se considerarmos que, na década de 1860, as técnicas modernas de purificação da água para consumo humano eram incipientes e a captação em nascentes reduzia o risco de transmissão de doenças $^{8}$. Outro fator que, possivelmente, influenciou na escolha do local de captação foi a viabilidade da distribuição por gravidade, opção que significava uma grande economia em relação ao uso de máquinas para elevação das águas.

No decorrer do século XX, o crescimento urbano e industrial, na Região Metropolitana de Porto Alegre, não foi acompanhado por investimentos e trabalhos técnicos necessários para a coleta e tratamento do esgoto doméstico. Consequentemente, o quadro de poluição hídrica atingiu níveis críticos. Segundo os dados apresentados por Freitas (1962) em sua Tese intitulada O destino dos esgotos em Porto Alegre em face da poluição do Guaíba, a rede de esgoto da cidade era insuficiente e estava sobrecarregada. O mesmo autor descreve as áreas da capital que, em 1962, ainda estavam desprovidas da rede.

Toda a zona não servida por esgoto sanitário (Menino Deus, entre a Avenida Getúlio Vargas e Praia de Bela, Partenón, Glória, Teresópolis, parte de Petrópolis, São João e Navegantes, da Rua Almirante Tamandaré para o Norte) despeja seus esgotos nos pluviais, após o tratamento precário feito em fossas sépticas domiciliárias, ou despeja os extravasores destas fossas nas sargetas, lá onde nem esgoto pluvial existe, ou ainda é servida por fossas móveis, os malfadados cubos. (FREITAS, 1962, p. 19).

$\mathrm{Na}$ citação trazida acima, percebe-se que a ausência da rede coletora do esgoto doméstico era suprida por práticas como o uso de fossas sépticas, o descarte dos dejetos na rede fluvial e a remoção em cubos - recurso que ainda era usado na periferia da cidade. No entanto, a inexistência da rede coletora em uma extensa área do sítio urbano porto-alegrense não era o único fator que provocava a poluição do Guaíba. As águas procedentes do rio dos Sinos, do Caí e, principalmente, do Gravataí, apresentavam um elevado índice de poluentes.

De fato, o problema do descarte do esgoto in natura, no Guaíba ou nos seus principais afluentes, havia se tornado um problema grave para Porto Alegre. E na condição de professor de Higiene da Habitação e Saneamento da Cidade, na

\footnotetext{
${ }^{8}$ A possibilidade de transmissão de doenças através do consumo de águas poluídas já estava presente na antiguidade e foi registrada na obra de Hipócrates, intitulada Ares, Águas e Lugares. A mesma possiblidade influenciou nas práticas da chamada medicina neohipocrática, no decorrer dos séculos XVII, XVIII e XIX. A partir de 1854, ano da publicação da obra de John Snow, intitulada Sobre a maneira de transmissão do Cólera (SNOW, 1999), cresceu o interesse da comunidade científica pelo tema.
} 
Universidade Federal do Rio Grande do Sul, Freitas defendeu a necessidade de medidas para conter o processo de poluição hídrica que estava em curso.

\begin{abstract}
Qualquer solução parcial, como por exemplo: mudança dos pontos de captação das águas de abastecimento, campanha educativa da população, para evitar banho nas águas poluídas, etc. são meros paliativos, pois aumentando a população e o parque industrial da cidade, dentro de mais alguns anos, a poluição se estenderá às zonas até agora inatingidas. [...]. A solução definitiva e radical será, pois, EVITAR a poluição do rio (FREITAS, 1962, p. 29).
\end{abstract}

A solução defendida pelo professor Freitas foi protelada ao longo dos anos 70, quando os investimentos na rede de esgoto de Porto Alegre foram inexpressivos. Naquele contexto, o crescimento econômico via industrialização era a prioridade da Ditadura Civil-Militar e, assim como ocorreu com outras grandes cidades do Brasil, Porto Alegre ampliou o seu parque industrial. A instalação de novas indústrias e a concentração demográfica na capital e na Região Metropolitana de Porto Alegre provocaram o agravamento da poluição no Guaíba.

O déficit crescente no atendimento às necessidades de abastecimento de água e de instalação de esgotos, face ao aumento acelerado na população da cidade, já vinha sendo uma preocupação da administração municipal de Porto Alegre desde o início da década de 1950. Nesse período, a municipalidade determinou que o Departamento Municipal de Água e Esgoto (DMAE) priorizasse a ampliação da oferta de água potável. Para atender essa prioridade, o DMAE destinou a maior parte dos recursos gerados pelo serviço para a ampliação da sua capacidade de fornecimento de água. A modernização e a expansão da rede distribuidora também absorveu os empréstimos obtidos junto ao Banco Interamericano de Desenvolvimento (BID), através de um contrato de financiamento assinado em 1964.

O trabalho do DMAE foi pesquisado por Antônio Dias Prestes na sua Dissertação de Mestrado, cujo foco eram as iniciativas para despoluição do Guaíba (PRESTES, 2012). Nessa Dissertação, o autor consultou documentos administrativos e técnicos do DMAE, analisou as relações entre a municipalidade e o governo estadual na área do saneamento e abordou a posição da imprensa local sobre as discussões em torno da poluição hídrica no Guaíba. Com base nos dados coletados e interpretados por Prestes, podemos afirmar que, no decorrer dos anos 50, 60 e 70, o sistema de esgoto ficou em segundo plano na política de saneamento conduzida pela municipalidade. No 
entanto, isso não significa dizer que não havia uma preocupação com o problema da degradação das águas do Guaíba.

No ano de 1966, o DMAE elaborou um Plano Diretor Geral para os Esgotos Sanitários (PGE), o qual previa um aumento substancial na área urbana servida pela rede de esgotos cloacais. O plano foi aprovado pelo BID em 1967. Tendo em conta esse cenário restritivo, o PGE não contemplava o envio dos esgotos coletados para uma estação de tratamento. Entretanto, recomendava o seu lançamento in natura no canal de navegação do Guaíba, através de um emissário subfluvial, a partir da Ponta da Cadeia, na extremidade da península, onde está situado o centro da cidade. Esse emissário deveria substituir o despejo realizado diretamente no lago junto à Ponta do Melo.

No ano de 1970, o DMAE criou um grupo de trabalho com o objetivo de estudar a poluição do Guaíba. Em novembro de 1971, os resultados de uma primeira avaliação da qualidade das águas desse lago e de seus principais formadores foram apresentados pelo DMAE durante o $17^{\circ}$ Congresso Brasileiro de Química realizado em Porto Alegre. Os seus técnicos asseguraram que a água do lago era adequada para o abastecimento da população, após o devido tratamento, mas alertaram para os impactos, num futuro próximo, da poluição gerada pelo crescente despejo de efluentes não tratados das diversas indústrias da Região Metropolitana. As condições de balneabilidade das praias de Porto Alegre não foram, então, discutidas.

Enquanto o DMAE estudava a viabilidade do tratamento das águas do Guaíba, o processo de poluição avançava em ritmo acelerado. Uma parte da poluição era gerada pelo esgoto doméstico das cidades que formam a Bacia Hidrográfica do Guaíba; outra parte era gerada pelos efluentes industriais das respectivas cidades (FREITAS, 1962; RIO GRANDE DO SUL, 1972; CANTERGI, 1975) ${ }^{9}$. E havia, ainda, uma poluição hídrica decorrente do uso indiscriminado de agrotóxicos nas lavouras da região denunciado pela Associação Gaúcha de Proteção ao Ambiente Natural (AGAPAN) na década de 1970. O conjunto de práticas poluidoras e a insuficiência de ações do poder público, voltadas para a preservação dos mananciais hídricos, geraram graves prejuízos à atividade dos pescadores residentes nas ilhas do Delta do Jacuí. A redução da

\footnotetext{
${ }^{9}$ Os estudos técnicos sobre a poluição hídrica realizados no Rio Grande do Sul dos anos 60 e 70 indicam que uma parte expressiva dos resíduos industriais e do esgoto doméstico lançados no Guaíba procedia da Bacia Hidrográfica do Rio dos Sinos e da Bacia Hidrográfica do Rio Gravataí. No caso específico da Bacia Hidrográfica do Rio dos Sinos, o problema da poluição hídrica foi registrado no "Planejamento Hidrológico do Rio dos Sinos" elaborado pelos técnicos alemães e publicado em 1969. O mesmo problema também recebeu atenção da imprensa leopoldense e foi discutido no "I Ciclo de Debates sobre a Poluição do Rio dos Sinos", realizado pela Câmara Municipal de São Leopoldo, em 1971 (HARRES; RÜCKERT, 2015).
} 
quantidade de peixes levou ao gradual abandono da pesca e à busca de alternativas para o sustento dos pescadores.

Outra consequência, recorrente do processo de poluição hídrica ocorrido na Região Metropolitana de Porto Alegre, foi a interdição das praias do Guaíba - fato ocorrido em novembro de 1973, por decisão da Secretaria Estadual de Saúde. Prestes pesquisou sobre esse assunto nos jornais Correio do Povo, Folha da Tarde e Zero Hora, e constatou que a maior parte dos textos publicados sobre a poluição do Guaíba careciam de uma crítica mais consistente ao trabalho do governo na área do saneamento. Apesar de ser um fato relevante, a notícia sobre a interdição das praias não foi acompanhada de qualquer manifestação em editorial e, embora presente na capa do jornal Zero Hora, teve um destaque mínimo, em comparação com outras manchetes do respectivo período. Apenas o jornal Folha da Tarde ilustrou a sua matéria com as placas que seriam colocadas comunicando a interdição das praias (PRESTES, 2012).

Se a interdição das praias do Guaíba foi um assunto pouco explorado pela imprensa, o mesmo não deve ser dito sobre as discussões em torno da fábrica de papel Borregaard. Instalada na cidade de Guaíba, às margens do lago, em frente à Zona Sul de Porto Alegre, a fábrica começou a operar em março de 1972. Sem dispositivos adequados para o tratamento dos seus resíduos, ela lançou um grande volume de substâncias químicas no lago e provocou desconforto na população com as suas emissões de gases sulfúricos. Esse quadro levou o governo do estado, frente a uma campanha conduzida pela imprensa e embasada pelos argumentos dos ambientalistas, a decretar a interdição temporária da empresa, exigindo a instalação dos equipamentos necessários para o controle da poluição que ela provocava.

A polêmica gerada em torno da Borregaard e a discussão sobre os fortes impactos ambientais provocados pela indústria contribuiu para fortalecer a crítica à degradação ambiental que já estava em curso no Rio Grande do Sul ${ }^{10}$. Dessa forma, ainda em 1972, a Assembleia Legislativa do Estado do Rio Grande do Sul instalou uma Comissão Parlamentar Especial (CPE) para estudar os problemas da poluição e do meio ambiente. Os documentos produzidos e publicados pela Comissão Parlamentar Especial (RIO GRANDE DO SUL, 1972) são relevantes para compreensão das mudanças que estavam em curso na relação da sociedade porto-alegrense com as águas do Guaíba.

\footnotetext{
${ }^{10}$ Convém lembrarmos que a crítica à degradação ambiental no Rio Grande do Sul ganhou impulso a partir do trabalho realizado por Luiz Henrique Roessler e pela União Protetora da Natureza (UPN), entidade criada em 1955. A mesma crítica também encontrou respaldo na obra do Padre Balduíno Rambo (RÜCKERT, 2007; PRADO, 2011; PEREIRA, 2013).
} 
Nas sessões de abertura da CPE, o ambientalista José Lutzenberger fez uma longa explanação sobre a ecologia como "ciência da sobrevivência" (LUTZENBERGER, 1972). Ele discorreu sobre os efeitos do modelo econômico vigente, o qual privilegiava o lucro e os resultados de curto prazo, à custa da preservação do meio ambiente. Lutzenberger lamentou que a preocupação com os empregos fosse maior do que a preocupação com a degradação ambiental; e descreveu, de uma forma bem precisa, conquanto em tons dramáticos, os efeitos de uma prática que poderíamos chamar de modelo "extrativista" do uso dos bens naturais (PRESTES, 2012) $)^{11}$.

A poluição hídrica foi um dos principais tópicos abordados na CPE. Uma das sessões dedicadas a esse tema referiu-se, especificamente, ao problema da poluição do Guaíba causada pelo lançamento do esgoto cloacal não tratado e aos planos do DMAE para a sua solução. Nessa ocasião, o seu diretor geral, engenheiro Alfredo Cestari, alertou para as ameaças ao abastecimento de água, num futuro próximo, caso não fossem tomadas medidas para o controle e tratamento dos esgotos domésticos e industriais no Guaíba e afluentes. No início de seu depoimento, Cestari afirmou que a poluição do lago ainda não era tão grande quanto se imaginava, mas atribuiu isso, exclusivamente, à sua grande capacidade de diluição dos despejos, e destacou a inexistência de maiores cuidados, até então, com a preservação do meio ambiente. $\mathrm{O}$ diretor geral confirmou o plano do DMAE quanto ao envio do esgoto doméstico in natura da cidade para o canal de navegação do Guaíba através de um emissário subfluvial, embora tivesse assegurado que todo o volume adicional de esgoto que viesse a ser gerado, a partir de então, só seria enviado ao lago após tratamento.

No prosseguimento dos trabalhos da CPE, quando questionado pelo presidente da comissão a respeito das razões pelas quais não estava previsto no plano de curto prazo do DMAE o tratamento do esgoto cloacal, o diretor Cestari alegou a inviabilidade financeira de conduzir simultaneamente a ampliação da rede de esgotos e a instalação de sistemas de tratamento. No seu relatório final, a CPE concluiu que "o Guaíba em muitas regiões ultrapassa o padrão normal, com um índice de poluição muito superior ao que as recomendações da OMS [Organização Mundial da Saúde] toleram”, e que "um banho no Guaíba pode abrir caminho para dezenas de doenças, provocadas pela

${ }^{11}$ O pensamento de José Lutzenberger, assim como a sua trajetória profissional e a sua atuação no movimento ambientalista sul rio-grandense foram detalhadamente pesquisados pela historiadora Elenita Malta Pereira (2016) na Tese intitulada A ética do convívio ecossustentável: uma biografia de José Lutzenberger. 
ingestão da água ou pelo simples contato.” Dentre as suas recomendações, estava a criação de um órgão governamental com a função específica de centralizar os programas de pesquisa e controle da poluição ambiental.

A interdição das praias foi justificada como medida preventiva diante do elevado índice de poluição hídrica. Apesar de pautada em um argumento sanitarista - a necessidade de proteger a saúde da população - a interdição das praias interrompeu um processo de interação entre a sociedade porto-alegrense e as águas do Guaíba. Segundo a Revista do Globo, em 1944, cerca de $15 \%$ dos habitantes da cidade procuravam as praias do Guaíba; a mesma revista informava que em 1965 “cerca de trinta mil pessoas se espalhavam pelas praias do lago nos dias mais quentes de verão." (PRESTES, 2012, p. 84).

\section{Iniciativas para a despoluição do Guaíba ${ }^{12}$}

Pensando nas práticas de despoluição hídrica como potencializadoras de "encontros" entre a sociedade porto-alegrense e o lago Guaíba, pretendemos abordar, nesta secção do artigo, um conjunto de iniciativas tomadas por parte dos poderes públicos, visando à recuperação ambiental do respectivo lago. Assim, importa analisarmos iniciativas de despoluição surgidas nas décadas de 1980 e 1990, destacando o Programa "Guaíba Vive" e o Programa "Pró-Guaíba".

Em 1989, a prefeitura de Porto Alegre lançou o "Guaíba Vive” propondo ações para recuperação do lago dentro dos limites territoriais do município. O programa foi concebido como uma iniciativa da prefeitura com foco ambiental, procurando conjugar ações localizadas na área do saneamento e controle de fontes poluidoras com um processo de conscientização e participação da comunidade. Inserido no contexto de mobilização da sociedade porto-alegrense em torno do Orçamento Participativo, o "Guaíba Vive" começou a ser debatido e formulado logo nos primeiros meses do governo da Administração Popular e os seus aspectos conceituais e objetivos foram sintetizados num folheto publicado sob o nome de Guaíba Vive (PINTO; MOHR, 1989). Está presente nessa publicação uma visão da degradação do meio ambiente como

\footnotetext{
${ }^{12} \mathrm{O}$ tema da despoluição do Guaíba foi pesquisado por Antônio João Dias Prestes - um dos coautores deste artigo. Nesta seção do artigo, destacamos alguns dados originalmente apresentados na Dissertação de Mestrado intitulada $O$ rio se renova, permitindo que os erros do passado sejam corrigidos. (PRESTES, 2012). O mesmo tema também pode ser consultado no artigo intitulado Uma iniciativa para recuperação ambiental em espaços urbanos: o programa "Guaíba Vive", Porto Alegre, 1989-2004. (PRESTES, 2013).
} 
um problema que tem raízes de ordem cultural, as quais incluiriam, num sentido mais amplo, o fenômeno do crescimento acelerado das aglomerações urbanas, não acompanhado pela percepção de seus efeitos sobre os recursos naturais. Como decorrência, a sua superação da degradação ambiental demandava um esforço de conscientização e não apenas a realização de investimentos públicos. Desse modo, o folheto apresentou uma visão mais pragmática acerca das questões ambientais, contemplando nas suas propostas o conceito da "sustentabilidade"13.

Estabeleceu-se um primeiro objetivo que o governo municipal acreditava estar ao alcance de seus recursos: a recuperação das praias da Zona Sul da cidade. Em sua narrativa histórica, o folheto destacava o papel desempenhado pelos primeiros militantes e organizações ambientalistas no combate à poluição do Guaíba; opondo esse envolvimento à falta de vontade política do Estado para a aplicação das legislações ambientais já existentes. Estava presente, também, no respectivo folheto, a preocupação com os efeitos da degradação do lago e a percepção de que a poluição estava provocando o afastamento dos porto-alegrenses do convívio com as águas do Guaíba.

O primeiro resultado mais expressivo do "Guaíba Vive" apresentado à população de Porto Alegre foi a recuperação ambiental da praia do Lami, situada no extremo sul do município, a cerca de 40 quilômetros do centro da cidade. O projeto de recuperação desse balneário foi iniciado no ano de 1990, com a realização de um levantamento das atividades desenvolvidas nas microbacias dos arroios existentes na região. O monitoramento da qualidade das águas, então realizado pelo DMAE, constatou que a sua contaminação era causada, na maior parte, pelos próprios resíduos domésticos da população. Como solução para o problema, o DMAE recomendou o tratamento do esgoto local, de modo a preservar a vocação do bairro para atividades de lazer e turismo. O sistema proposto foi colocado em operação em dezembro de 1992, momento em que a prefeitura anunciou a entrega da praia do Lami, novamente balneável, para a população de Porto Alegre ${ }^{14}$.

\footnotetext{
13 Uma interessante discussão sobre os vários significados e interpretações do conceito de "sustentabilidade" pode ser encontrada na obra de José Eli da Veiga (2006), intitulada Desenvolvimento Sustentável: o desafio do século XXI. O mesmo tema pode ser analisado a partir do conceito de "racionalidade ambiental" construído por Enrique Leff para interpretar as mudanças decorrentes da crise ambiental no comportamento social e no campo científico (LEFF, 2006).

${ }^{14}$ Os investimentos em saneamento realizados pelo DMAE foram de US\$ 2,3 milhões e o projeto de recuperação também contemplou outras obras de infraestrutura urbana, como posto de saúde e coleta regular de lixo, além de instalações para permitir um melhor uso da praia pela população.
} 
Outra obra do DMAE contemplada no "Guaíba Vive" visava à melhoria nas condições de saneamento do bairro Ipanema. Como uma primeira etapa de um sistema para coleta e tratamento de esgoto cloacal da Zona Sul da cidade consistiu na ligação das principais fontes de contribuição locais a um interceptor capaz de reter e depurar essa carga em períodos secos, o esgoto não tratado só seria lançado no lago em situações com maior incidência de chuvas. Foi concluída em novembro de 1996 e os resultados obtidos não foram suficientes para recuperar a balneabilidade de Ipanema, fortemente influenciada pela contaminação do Guaíba pelos esgotos das demais áreas da cidade, conquanto tenham levado a melhorias pontuais na qualidade das águas dessa praia.

O último grande investimento dos governos da Administração Popular dentro do subprograma de saneamento do "Guaíba Vive" foi a construção da Estação de Tratamento de Esgoto (ETE) Belém Novo, que começou a operar em setembro de 2002. A cobertura por esgoto tratado de Porto Alegre, que subira para 25\% dois anos antes com a implantação da ETE São João/ Navegantes, integrando o "Pró-Guaíba", chegou a $27 \%$ com a entrada em funcionamento da ETE Belém Novo.

O "Guaíba Vive" também contemplou uma série de iniciativas dentro de seus subprogramas de paisagismo e urbanismo, desenvolvimento ecológico, educação ambiental e eventos. O primeiro tinha como objetivos a valorização do convívio das populações com a orla, por meio de projetos e obras de urbanismo e paisagismo; e previa a recuperação para o uso público de espaços nessa parte da cidade que haviam sido tomados por ocupações irregulares. O segundo tinha, dentre os seus objetivos, o aproveitamento turístico-ecológico de paisagens e ecossistemas do Guaíba, visto como um meio não apenas para a conscientização sobre a preservação do meio ambiente, mas para a geração de emprego e renda, através de atividades como o turismo ecológico e a produção e comercialização de artesanato, pelas comunidades vivendo nas áreas beneficiadas. Ele buscava, também, "o disciplinamento de atividades comerciais nos balneários recuperados, adequando-as a um perfil compatível com a preservação paisagística”. O subprograma de educação ambiental, por sua vez, enfeixava uma série de objetivos e iniciativas tais como a criação de fóruns de participação comunitária, visando à "conscientização e [ao] engajamento da população no resgate do Guaíba", atividades de educação ambiental e conscientização nas escolas e atividades culturais visando à reaproximação da cidade com o lago. 
Os resultados obtidos pelo "Guaíba Vive" apresentaram reflexos, ainda que limitados, na vida social e cultural da cidade. Os trabalhos realizados pelo programa sinalizaram para a possibilidade de retomar o uso praiano do lago e possibilitaram a remoção de ocupações irregulares em determinados locais da orla do Guaíba ${ }^{15}$. A população foi beneficiada com as obras de saneamento e com a volta da balneabilidade das praias do Lami, e, em parte, de Belém Novo. No entanto, a continuidade da recuperação do Guaíba ainda demandava a realização de obras de maior vulto e dependia da implantação de mecanismos legais para uma gestão integrada das águas na Região Metropolitana de Porto Alegre.

As experiências de despoluição do Guaíba, conduzidas pela municipalidade porto-alegrense, coexistiram com experiências promovidas pelo governo estadual a partir do Programa "Pró-Guaíba", implantado em 1989. As prioridades do programa apontavam para recuperação ambiental e o desenvolvimento sustentável da Bacia Hidrográfica do Guaíba e as suas diretrizes contemplavam o princípio da cooperação entre as municipalidades da Região Metropolitana de Porto Alegre o governo estadual.

Para financiar o "Pró-Guaíba", o governo do Rio Grande do Sul buscou recursos do Banco Interamericano de Desenvolvimento (BID). O contrato do governo estadual com o BID foi assinado em 1995 depois da renegociação da dívida do Estado com a União Federal. Nesse contrato, o governo estadual assumiu o compromisso de investir no saneamento uma contrapartida de $40 \%$ do valor concedido pelo BID.

A mobilização do governo estadual sul rio-grandense, visando à recuperação ambiental do Guaíba e de sua bacia hidrográfica, ocorreu em um contexto marcado pelo processo de redemocratização política do Estado brasileiro e pela crescente preocupação com as questões ambientais. Para atender demandas apresentadas pelo movimento ambientalista, foram introduzidos na Constituição Federal de 1988 e nas novas constituições estaduais, princípios voltados para o uso sustentável de recursos naturais como as águas superficiais e subterrâneas, que passavam a ser reconhecidas como bens de propriedade do Estado $^{16}$. Dentre os principais elementos da política de gestão hídrica

\footnotetext{
${ }^{15}$ Em alguns casos, a remoção de habitações irregulares na orla do Guaíba provocou manifestações de resistência. A intervenção da municipalidade não agradou os proprietários dos bares em Ipanema e gerou insatisfação das comunidades que viviam nessas áreas.

${ }^{16}$ A Constituição Federal de 1988 estabeleceu a propriedade estatal das águas e definiu uma esfera federal de domínio das águas (rios de fronteira e rios que atravessam vários estados) e esferas estaduais (rios internos a cada estado e águas subterrâneas). O texto constitucional abriu o caminho para a instituição de sistemas de gestão de recursos hídricos estaduais e incentivou a participação da sociedade civil nos respectivos sistemas (JACOBI; FRACALANZA, 2005).
} 
implantada a partir da Constituição de 1988, importa destacarmos o chamado "princípio usuário pagador", adotado como estratégia para viabilizar o financiamento da conservação e recuperação ambiental; e a proposta de definição das prioridades de investimentos a partir de comitês de bacias hidrográficas ${ }^{17}$.

No final dos anos 80, a demanda de vários setores da sociedade gaúcha pela recuperação ambiental do Guaíba foi levada em conta durante o processo constituinte estadual. Isso resultou a inclusão nas disposições transitórias da Constituição Estadual de $1989^{18}$ de um artigo prevendo a destinação de recursos para a despoluição da Bacia Hidrográfica do Guaíba com a seguinte redação:

\begin{abstract}
Art. 56 - A lei que instituir o plano plurianual deverá prever, nos próximos vinte anos, recursos destinados a programas de despoluição do rio Guaíba e demais rios da Região Metropolitana e à manutenção da potabilidade e balneabilidade restabelecidas.

Parágrafo único - A lei de diretrizes orçamentárias e os orçamentos anuais especificarão os recursos necessários, anualmente, para a implementação do programa previsto neste artigo. (GOVERNO DO ESTADO DO RIO GRANDE DO SUL, 1989, p. 83).
\end{abstract}

Juridicamente, a República Nova criou dispositivos para aprimorar a atuação do poder público na gestão das águas, tanto no plano nacional, quanto no plano estadual. Mas na prática as leis não solucionavam o problema da insuficiência de recursos públicos para obras e serviços de saneamento. E na cidade de Porto Alegre, além das limitações financeiras, a década de 1980 encerrou-se com a permanência de um impasse de ordem técnica: como tratar o esgoto doméstico da região central de Porto Alegre, lançado in natura, desde os anos de 1970, no canal de navegação do grande lago, através de emissário instalado na Ponta da Cadeia.

\footnotetext{
${ }^{17}$ A reformulação da política de gestão hídrica na Nova República ocorreu num contexto de retração dos investimentos públicos. Na área do saneamento, além das restrições à obtenção de recursos financeiros, a substituição do sistema de financiamento criado pelo Regime Militar - baseado no trinômio Banco Nacional da Habitação (BNH) / Plano Nacional de Saneamento (PLANASA) / Companhias Estaduais de Saneamento (CESBs) - demonstrou-se problemática. A contratação de novos financiamentos utilizando os recursos do FGTS esteve suspensa até o ano de 1995, quando foi criado mecanismo que permitiu a estados e municípios oferecerem as receitas tarifárias e a penhora de seus ativos no setor como garantia para contrair novas dívidas (PRESTES, 2012, p. 206).

${ }^{18}$ A Constituição do Rio Grande do Sul de 1989 instituiu, através de seu artigo 171, o sistema estadual de recursos hídricos. Posteriormente, a Lei Estadual n. 10.350/1994, regulamento o respectivo sistema e estabelecendo uma política de gestão das águas baseada em 4 princípios: " gestão das águas através de um Sistema Estadual de Recursos Hídricos [...]; adoção da bacia hidrográfica como unidade básica de planejamento e intervenção; estabelecimento da outorga e tarifação dos recursos hídricos (cobrança pela retirada e despejo de efluentes); reversão para a respectiva bacia, de arrecadação da receita, devendo os recursos financeiros serem aplicados na própria gestão das águas da bacia" (GOVERNO DO ESTADO DO RIO GRANDE DO SUL, s/d, p. 4).
} 
A prolongada dúvida quanto ao tratamento do esgoto e a insuficiência dos recursos públicos disponíveis para o saneamento básico na Região Metropolitana de Porto Alegre foi acompanhada de um rápido agravamento na poluição das águas do lago Guaíba. Diante do quadro problemático, diferentes segmentos da sociedade local e setores técnicos do governo ligados ao meio ambiente mobilizaram-se para discutir alternativas de controle e redução da poluição hídrica. A mobilização avançou com a criação do Programa para o Desenvolvimento Racional, Recuperação e Gerenciamento Ambiental da Bacia Hidrográfica do Guaíba, implantado pelo governador Pedro Simon, através do Decreto $\mathrm{n}^{\circ} 33.360$, de 27 de novembro de 1989. O programa, que logo passou a ser conhecido como "Pró-Guaíba", não foi concebido, inicialmente, como um plano abrangente, ao contrário do que poderia sugerir o seu nome. O texto previa apenas ações voltadas para o saneamento básico. Posteriormente, depois de apresentado aos técnicos do Banco Interamericano de Desenvolvimento (BID), ele foi modificado para ganhar as características mais amplas de um plano voltado não apenas às ações pontuais de recuperação, mas também para a gestão sustentável da bacia hidrográfica do Guaíba $^{19}$.

O "Pró-Guaíba" foi desdobrado em seis subprogramas: (i) estruturação e base legal; (ii) diagnóstico, estratégias de manejo (hidrográfico, atmosférico e de solo) e sistemas de monitoramento ambiental; (iii) prevenção e controle da contaminação industrial e doméstica; (iv) manejo dos recursos naturais renováveis e das áreas rurais; (v) parques e reservas naturais; (vi) educação ambiental. Sob essa nova configuração, foi submetida uma carta-consulta, ainda em 1991, ao BID, cuja diretoria aprovou o contrato de financiamento em outubro de 1993. Durante todo esse período estava em curso a renegociação das dívidas do estado do Rio Grande do Sul com o governo federal, sendo obtido o aval da União para a assinatura do contrato com o BID apenas em julho de 1995.

Os recursos para custear o primeiro módulo do "Pró-Guaíba" no valor de US\$ 220,5 milhões foram liberados em janeiro de 1996, dos quais $60 \%$ provenientes do financiamento do BID, e os restantes $40 \%$ das contrapartidas do estado e de outros coexecutores, como a prefeitura de Porto Alegre. Estimava-se, então, que a recuperação total da bacia hidrográfica do Guaíba envolveria um dispêndio total de cerca de 1 bilhão

\footnotetext{
${ }^{19} \mathrm{O}$ impacto das recomendações feitas pelo BID no programa inicialmente apresentado pelo governo estadual foi descrito no documento intitulado Baía de todas as águas: preservação e gerenciamento ambiental na Bacia Hidrográfica do Guaíba (SECRETARIA DA COORDENAÇÃO E PLANEJAMENTO DO ESTADO DO RIO GRANDE DO SUL, 1998).
} 
de dólares que seriam aplicados em quatro ou cinco módulos. Previsto para ser desenvolvido num horizonte de 15 a 20 anos, o programa demonstrou uma preocupação técnica com as diversidades de problemas existente nas oito sub-bacias do lago Guaíba e, ao mesmo tempo, registrou as limitações financeiras do estado do Rio Grande do Sul.

Ainda que o programa tivesse adotado essa configuração mais ampla, uma grande parte dos recursos do primeiro módulo do "Pró-Guaíba", quase 40\% do total, foi destinada para obras de esgotamento sanitário em Porto Alegre e na Região Metropolitana. Dentre as obras realizadas, destacam-se duas estações de tratamento de esgoto e cerca de 600 quilômetros de redes coletoras, beneficiando 250 mil pessoas nos municípios de Gravataí e Cachoeirinha; além dos já mencionados sistemas da ETE (Estação de Tratamento de Esgotos) São João/Navegantes e da Zona Sul de Porto Alegre, no Bairro de Ipanema. Não foi possível incluir nessa primeira fase o sistema de tratamento dos esgotos da região central da capital devido ao impasse ainda então existente quanto à solução técnica a ser adotada para o tratamento e a disposição final do efluente tratado.

Um dos subprogramas do "Pró-Guaíba" contemplava os parques e reservas naturais, tendo como um dos objetivos principais a manutenção da biodiversidade através da proteção de áreas representativas dos ecossistemas mais frágeis da região. Sua execução estava sob responsabilidade da Fundação Zoobotânica do Rio Grande do Sul (FZB) e do Departamento de Recursos Naturais Renováveis do Rio Grande do Sul (DRNR). O diagnóstico inicial indicou que apenas $0,6 \%$ da área total da bacia hidrográfica estavam protegidas por áreas de conservação, mas a maior parte destas ainda não estava efetivamente implantada. No Módulo I, foram incluídos dois projetos, visando à consolidação de quatro áreas consideradas de grande importância ecológica na Região Metropolitana de Porto Alegre: (1) o Jardim Botânico da capital; (2) o Parque Zoológico, situado entre os municípios de Sapucaia do Sul e São Leopoldo; (3) o Parque Estadual Delta do Jacuí, que compreende áreas nos municípios de Eldorado do Sul, Canoas, Triunfo e Porto Alegre; (4) e o Parque Estadual de Itapuã, em Viamão. Dessas quatro áreas, o Delta do Jacuí era o que apresentava (e ainda apresenta) maior concentração de problemas socioambientais, sobretudo nas ilhas situadas em frente ao centro da cidade de Porto Alegre, que correspondem ao bairro Arquipélago.

Os investimentos previstos para o Parque Estadual do Delta do Jacuí diziam respeito à implantação de infraestrutura administrativa, cultural e de lazer, à avaliação da fauna e da flora existentes e ao zoneamento das áreas ocupadas para posterior 
adequação ao plano de manejo. O ecossistema do Delta do Jacuí ocupa uma área de aproximadamente 16 mil hectares e apresenta características bastante complexas devido ao fato de abrigar uma das poucas áreas com flora e fauna nativas preservadas, compondo uma paisagem de banhados em meio a uma aglomeração urbana de quase três milhões de habitantes. O conjunto de ilhas exerce um papel muito importante no equilíbrio natural da Região Metropolitana na medida em que a sua vegetação contribui para estabilizar a temperatura e a umidade e com seus banhados retendo as águas em épocas de chuvas, minimizando a ocorrência das enchentes.

A área do Delta abriga uma população heterogênea que inclui comunidades de pescadores, famílias de baixa renda (muitos vivendo da coleta e reciclagem do lixo urbano) e moradores que possuem casas para veraneio às margens de suas águas. A população total do bairro Arquipélago cresceu nas últimas décadas, chegando a 5.100 pessoas no censo de 2000. Nessas condições, as iniciativas no sentido de estabelecer um disciplinamento na utilização das diversas áreas dessa unidade de conservação provocaram reações de moradores locais - eventuais ou permanentes - e produziram discussões envolvendo setores do poder público e o movimento ambientalista ${ }^{20}$.

A outra grande unidade de conservação contemplada pelo "Pró-Guaíba" foi o Parque Estadual de Itapuã, ocupando 5,6 mil hectares no município de Viamão na confluência entre a margem esquerda do lago Guaíba e a laguna dos Patos, cerca de 60 quilômetros ao sul da capital. Região com paisagens belas e variadas, apresentando praias e morros, ladeados por formações ainda preservadas de flora e fauna da mata atlântica; ela também possui locais com valor histórico, como o próprio Farol de Itapuã, construído no século XIX, e a presença de sítios arqueológicos das tradições Umbu e Tupi-Guarani. A preservação dessa área com a criação de um parque estadual foi uma das primeiras reivindicações do "movimento ambientalista" no Rio Grande do Sul conduzida através de ONGs como a AGAPAN desde os anos 1970. Teve como seus focos principais, desde então, o fim das pedreiras que lá funcionavam ilegalmente, bem como a caça a animais em extinção, como os bugios, e a ocupação de suas praias por casas de veraneio. O governo do Rio Grande do Sul decretou a criação do Parque Estadual de Itapuã em 1973, posteriormente, em 1991 o Estado providenciou ações para

\footnotetext{
${ }^{20}$ A implantação do Parque do Delta do Jacuí tem sido objeto de vários trabalhos no âmbito acadêmico, alguns dos quais abordam as inter-relações existentes entre as questões sociais e as ambientais, explorando o processo que o antropólogo José Sérgio Leite Lopes classificou como "ambientalização" de conflitos sociais (LOPES, 2006). Nessa perspectiva, destacam-se os trabalhos de Devos (2007) e Cardoso (2010).
} 
interromper as atividades irregulares na área e para remover cerca de 800 casas de veraneio lá instaladas clandestinamente. Tendo como objetivo fazer com que as autoridades tomassem as medidas necessárias para viabilizar a implantação do parque foi criada, em 1985, uma comissão integrada por representantes de ONGs de defesa do meio ambiente e estudantes universitários: a Comissão de Luta pela Efetivação do Parque Estadual de Itapuã. Em 1997, com o aporte dos recursos do Módulo I do "PróGuaíba", o governo estadual iniciou o processo de efetiva implantação do parque, que incluiu o pagamento de indenizações para antigos proprietários, bem como o cadastramento e remoção dos pescadores que lá viviam, aos quais foi permitido que continuassem a pescar naquela área. O Parque Estadual de Itapuã foi reaberto à visitação pública em 2002 depois da contratação de pessoal especializado e da instalação de infraestrutura de administração, controle e lazer, como a instalação de vestiários e churrasqueiras nas três praias liberadas ${ }^{21}$.

O "Pró-Guaíba" foi interrompido por tempo indeterminado ao final de sua primeira etapa, em 2004, devido à falta de condições financeiras do estado do Rio Grande do Sul em arcar com a sua contrapartida nos investimentos necessários para o seu prosseguimento. A quebra de continuidade vem tendo reflexos negativos em importantes iniciativas nessa bacia hidrográfica, a qual concentra dois terços da população do estado do Rio Grande do Sul. Sem a continuidade dos investimentos em saneamento básico que estavam previstos no seu Módulo II, os moradores da Região Metropolitana de Porto Alegre terão de conviver por mais tempo com a paisagem degradada das águas do Guaíba.

\section{Considerações finais}

A história dos "encontros" e "desencontros" entre Porto Alegre e as águas do Guaíba é demasiadamente complexa e permanece inacabada. Uma parte dessa história diz respeito à busca pela água potável, outra parte diz respeito ao problema da poluição hídrica nas suas múltiplas origens.

A poluição do lago Guaíba apresentou diversas etapas e pode ser considerada uma experiência de "desencontro" da população porto-alegrense com as águas. A construção da Ferrovia do Riacho para afastar os despejos fecais do centro de Porto

\footnotetext{
${ }^{21}$ As praias do Parque Estadual de Itapuã liberadas para visitação são a da Pedreira e a das Pombas, localizadas no Guaíba, e a paria de Fora, localizada na Laguna dos Patos.
} 
Alegre e a posterior construção da rede coletora de esgoto (inaugurada em 1912) foram ações pautadas na preocupação com a higiene e com a salubridade urbana. Naquele contexto, as discussões sobre a necessidade de tratamento do esgoto já estavam em curso na comunidade científica internacional, mas na Porto Alegre da primeira metade do século XX, a prioridade na área do saneamento era expansão do abastecimento de água.

Diante de um prolongado período sem investimentos públicos no tratamento do esgoto gerado pela capital, e numa conjuntura de intensificação das atividades industriais na Região Metropolitana de Porto Alegre, a poluição do Guaíba agravou-se e provocou a reação de segmentos da sociedade local, sobretudo do movimento ambientalista. No decorrer dos anos 1970, fatos como o fortalecimento do movimento ambientalista gaúcho, a interdição das praias e o impacto provocado pelos resíduos da Borregaard criaram uma conjuntura favorável para a discussão das relações entre a cidade de Porto Alegre e as águas do Guaíba.

Considerando a extensa temporalidade do tema contemplado, acreditamos ser pertinente enfatizar a descontinuidade entre as políticas de despoluição, implantadas nas décadas finais do século passado, e as primeiras iniciativas para prover Porto Alegre de serviços de saneamento básico, executadas no final do século XIX e começo do XX. Tais iniciativas estavam inseridas no contexto da "politização da higiene" e, consequentemente, priorizavam a oferta de água potável e a manutenção da higiene pública - o que incluía afastar os despejos fecais da área urbana. O novo ciclo de iniciativas para o saneamento e o controle da poluição do Guaíba, por sua vez, iniciouse no contexto de configuração do "ambientalismo", dentro do qual encontramos uma forte crítica à degradação dos recursos naturais e uma preocupação com os impactos socioambientais decorrentes das intervenções humanas no ambiente.

Cronologicamente, a década de 1970 marca o começo de uma mudança na percepção sobre o uso das águas do Guaíba. Nessa década, a interdição das praias foi uma experiência de "desencontro" entre a população local e o lago. As consequências do "desencontro" incluem, além do prolongado período em que a população vem sendo privada do pleno uso destas praias, a perda da memória do papel anteriormente exercido pelos balneários do Guaíba no cotidiano de Porto Alegre. Ainda nos anos 70, o movimento ambientalista exerceu um papel importante nas discussões sobre a poluição hídrica, defendendo a necessidade de contenção da poluição industrial e de investimentos públicos no tratamento do esgoto. Sob a liderança do movimento 
ambientalista, iniciou-se um processo de "reencontro" de Porto Alegre com as águas do Guaíba.

Os dois programas de despoluição do Guaíba destacados no artigo alcançaram resultados modestos, dentre os quais podemos citar a elevação da cobertura por esgotos sanitários tratados de Porto Alegre para 27\% do total em 2002 e a recuperação plena da balneabilidade apenas da praia do Lami, situada no extremo sul da capital, fora da sua zona urbana. O "Pró-Guaíba" previa um investimento adicional de 172 milhões de dólares, mas o programa foi suspenso em 2004 em função do agravamento da situação das finanças públicas do Estado do Rio Grande do Sul.

Limitadas pela insuficiência de investimentos públicos, as iniciativas de despoluição desenvolvidas nas últimas décadas não foram suficientes para reverter o quadro de degradação do Guaíba. No entanto, elas representam um importante conjunto de experiências com ramificações no plano técnico, planto jurídico e social. No plano técnico, foram realizadas diversas obras para ampliar a coleta e o tratamento do esgoto e novos projetos aguardam verbas para execução; no plano jurídico, observamos avanços com a criação de leis voltadas para a gestão das águas e com a criação do Parque do Delta do Jacuí e Parque Estadual de Itapuã; além de um aprimoramento na cooperação entre as diferentes esferas do poder público - municípios, Estado e União. No plano social, iniciativas de despoluição do Guaíba provocaram um crescente interesse da população pelas questões ambientais e, indiretamente, possibilitaram a valorização do saneamento na agenda política e na imprensa local e influenciaram nas práticas de Educação Ambiental executadas na Região Metropolitana de Porto Alegre.

Considerando o saldo das experiências acumuladas na busca pelo "reencontro" com as águas do Guaíba, podemos afirmar que o problema da poluição hídrica excede os limites da cidade de Porto Alegre, configurando-se num problema regional, na medida em que uma parte expressiva dos efluentes (industriais ou domésticos) procede dos rios formadores do lago, sobretudo do rio dos Sinos e do rio Gravataí. Nestas condições, a solução para a degradação ambiental desse lago demanda esforços integrados dos municípios da Região Metropolitana de Porto Alegre.

Para que uma plena recuperação ambiental da bacia hidrográfica do Guaíba possa coexistir com a desejada universalização do saneamento básico serão necessários grandes investimentos públicos e um esforço de articulação entre as diferentes esferas do governo e a sociedade civil. 


\section{REFERÊNCIAS}

AB'SABER, Aziz. A sociedade urbano-industrial e o metabolismo urbano. In: GIANOTTI, Carlos Alberto (Org.). Prospectivas. À beira do novo milênio. São Leopoldo: UNISINOS, 1995. p. 9-21.

MENEGAT, Ronaldo (Coord.). Atlas Ambiental de Porto Alegre. Porto Alegre: UFRGS, 2006.

ÁVILA, Vladimir Ferreira de. Saberes históricos e práticas cotidianas sobre o saneamento: desdobramentos na Porto Alegre do século XIX (1850-1900). 2010. Dissertação (Mestrado em História) - Pontifícia Universidade Católica do Rio Grande do Sul, Programa de Pós-Graduação em História, Porto Alegre, 2010. Disponível em: $<$ http://repositorio.pucrs.br/dspace/bitstream/10923/3945/1/000425495-

Texto\%2BCompleto-0.pdf>. Acesso em: 28 de junho de 2015.

CANTERGI, Adolpho. A poluição das águas no Estado do Rio Grande do Sul. In: SECRETARIA ESPECIAL DO MEIO AMBIENTE. Encontro Nacional sobre a Proteção e Melhoria do Meio Ambiente. Brasília: Ministério do Interior/SEMA, 1975, p. 203-217.

CARDOSO, Patrícia Moreira. Conflitos socioambientais em áreas protegidas: Interesses e Estratégias nas Disputas pela Legitimidade na Redefinição do Parque Estadual do Delta do Jacuí. 2010. Dissertação (Mestrado em Desenvolvimento Rural) Universidade Federal do Rio Grande do Sul, Programa de Pós-Graduação em Desenvolvimento Rural, Porto Alegre, 2006. Disponível em: <http://hdl.handle.net/10183/10801>. Acesso em: 03 jul. 2010.

DEVOS, Rafael Victorino. A “questão ambiental” sob a ótica da antropologia dos grupos urbanos, nas ilhas do Parque Estadual Delta do Jacuí, Bairro Arquipélago, Porto Alegre, RS. 2007. Tese (Doutorado em Antropologia Social) - Universidade Federal do Rio Grande do Sul, Programa de Pós-Graduação em Antropologia, Porto Alegre, 2007. Disponível em: <http://hdl.handle.net/10183/8688>. Acesso em: 05 jul. 2015.

FREITAS, Amadeu Fagundes da Rocha. O destino dos esgotos de Porto Alegre em face da poluição do Guaíba. Tese apresentada à Faculdade de Arquitetura da Universidade do Rio Grande do Sul, no concurso para provimento do cargo para Professor Catedrático de Higiene da Habitação e Saneamento das Cidades. Porto Alegre: Universidade do Rio Grande do Sul, 1962.

GOVERNO DO ESTADO DO RIO GRANDE DO SUL. Constituição do Estado do Rio Grande do Sul. Porto Alegre: Assembleia Legislativa Estadual, 1983, p. 83. Disponível em: <http://www2.al.rs.gov.br/dal/LinkClick.aspx?fileticket=IiPguzuGBtw \%3D\&tabid=3683\&mid=5358> Acesso em: 15 out. 2016.

GOVERNO DO ESTADO DO RIO GRANDE DO SUL. Legislação de Recursos Hídricos. Porto Alegre: SEMA/FEPAM, s/d. 
HARRES, Marluza Marques; RÜCKERT, Fabiano Quadros Rückert. A natureza, o tempo e as marcas da ação humana: políticas públicas e ambiente em perspectiva histórica, São Leopoldo, RS. São Leopoldo: OIKOS, 2015.

HUYER, André. A Ferrovia do Riacho. Do sanitarismo a modernização de Porto Alegre. Porto Alegre: EVANGRAF, 2015.

JACOBI, Pedro Roberto; FRACALANZA, Ana Paula. Comitês de bacias hidrográficas no Brasil: desafios de fortalecimento da gestão compartilhada e participativa. Desenvolvimento e Meio Ambiente, Curitiba, n. 11-12, p. 41-49, jan./dez. 2005.

LEFF, Enrique. Racionalidade ambiental: a apropriação social da natureza. Rio de Janeiro: Civilização Brasileira, 2006.

LOPES, José Sérgio. Sobre processos de "ambientalização" dos conflitos e sobre os dilemas da participação. In: ECKERT, Cornelia; ROCHA, Ana Luiza Carvalho da; CARVALHO, Isabel Cristina de Moura (Org.). Horizontes Antropológicos. Ano 12, n. 25. Porto Alegre: PPGAS/UFRGS, 2006.

LUTZENBERGER, José. Ecologia como ciência da sobrevivência. In: RIO GRANDE DO SUL. Poluição e desenvolvimento. Porto Alegre: Assembleia Legislativa do Estado do Rio Grande do Sul, 1972. p. 41-42.

MACHADO, Janete da Rocha. História da via férrea na Zona Sul de Porto Alegre. Oficina do Historiador, Porto Alegre, v. 1, n. 1, p. 78-91, jun. 2010.

MATÉS-BARCO, Juan Manuel. La Conquista del agua. Historia económica del abastecimiento urbano.Jáen: Universidad de Jáen, 1999.

PEREIRA, Elenita Malta. Roessler - o homem que amava a natureza. São Leopoldo: OIKOS, 2013.

PEREIRA, Elenita Malta. A ética do convívio ecossustentável: uma biografia de José Lutzenberger. 2016. Tese (Doutorado em História) - Universidade Federal do Rio Grande do Sul, Programa de Pós-Graduação em História, Porto Alegre, 2016. Disponível em: <http://hdl.handle.net/10183/140281> Acesso em: 05 jan. 2017.

PINTO, Leila; MOHR, Udo. Guaíba Vive. Porto Alegre: Prefeitura Municipal de Porto Alegre, 1989.

PRADO, Daniel Porciuncula. A figueira e o machado: uma história das raízes do ambientalismo no Sul do Brasil e a crítica ambiental de Henrique Roessler. Coleção Pensar a História Sul-Rio-Grandense, 49. Rio Grande: FURG, 2011.

PRESTES, Antônio João Dias. O rio se renova, permitindo que os erros do passado sejam corrigidos. Estado e sociedade nas iniciativas para recuperação ambiental do Guaíba (1979-2004). 2012. Dissertação (Mestrado em História) - Universidade Federal do Rio Grande do Sul, Programa de Pós-Graduação em História, Porto Alegre, 2012. Disponível em: <http://hdl.handle.net/10183/61185>. Acesso em: 13 ago. 2016. 
PRESTES, Antônio João Dias. Uma iniciativa para recuperação ambiental em espaços urbanos: o programa "Guaíba Vive", Porto Alegre, 1989-2004. Revista LatinoAmericana de História, São Leopoldo, v. 2, n. 8, p. 94-114, 2013. Disponível: <http://projeto.unisinos.br/rla/index.php/rla/article/view/140/276>. Acesso em: 07 ago. 2016.

RECHENBERG, Fernanda. "Vamofalá do nosso Lami": estudo antropológico sobre memória coletiva, cotidiano e meio ambiente no bairro Lami, Porto Alegre. 2007. Dissertação (Mestrado em Antropologia Social) - Universidade Federal do Rio Grande do Sul, Programa de Pós-Graduação em Antropologia, Porto Alegre, 2007. Disponível em: <http://hdl.handle.net/10183/11256>. Acesso em: 2 maio 2016.

RIO GRANDE DO SUL. Poluição e desenvolvimento. Porto Alegre: Assembleia Legislativa do Estado do Rio Grande do Sul, 1972.

RÜCKERT, Fabiano Quadros. História e memória do ambientalismo no Vale do Rio dos Sinos. 2007. Dissertação (Mestrado em História) - Universidade do Vale do Rio dos Sinos, Programa de Pós-Graduação em História, São Leopoldo, 2007. Disponível em:<http://bdtd.unisinos.br/tde_arquivos/8/TDE-2008-02-12T134328Z-424/Publico/his toria\%20e\%20memoria.pdf $>$. Acesso em: 12 mar. 2015.

RÜCKERT, Fabiano Quadros. Os médicos e a higiene pública na imprensa do Rio Grande do Sul: entre a teoria dos miasmas e a teoria da transmissão hídrica das doenças. História Unicap, Recife, v. 1, n. 1, p. 74-90, jan./jul. 2014.

RÜCKERT, Fabiano Quadros. O saneamento e a politização da higiene no Rio Grande do Sul (1828-1930). Tese (Doutorado em História) - Universidade do Vale do Rio dos Sinos, Programa de Pós-Graduação em História, São Leopoldo, 2015. Disponível em: <http://www.repositorio.jesuita.org.br/bitstream/handle/UNISINOS/4990/Fabiano\%20 Quadro\%20R\%C3\%BCckert_.pdf?sequence=1\&isAllowed=y>. Acesso em: 04 fev. 2016.

SAINT'HILAIRE, Auguste de. Viagem ao Rio Grande do Sul. Porto Alegre: Martins Livreiro, 2002.

SECRETARIA DA COORDENAÇÃO E PLANEJAMENTO DO ESTADO DO RIO GRANDE DO SUL. Baía de todas as águas: preservação e gerenciamento ambiental na Bacia Hidrográfica do Guaíba. Porto Alegre: Secretaria Executiva do Pró-Guaíba, 1998.

SNOW, John. Sobre a maneira de transmissão do Cólera. São Paulo/Rio de Janeiro: HUCITEC/Abrasco, 1999.

TOCCHETTO, Fernanda B. Fica dentro ou joga fora. Sobre práticas cotidianas na Porto Alegre moderna oitocentista. São Leopoldo: OIKOS, 2010.

VEIGA, José Eli da. Desenvolvimento Sustentável: o desafio do século XXI. Rio de Janeiro: Garamond, 2006. 
WITTER, Nikelen Acosta. Males e Epidemias: sofredores, governantes e curadores no sul do Brasil (Rio Grande do Sul, século XIX). 2007. Tese (Doutorado em História) Universidade Federal Fluminense, Instituto de Ciências Humanas e Filosofia, Programa de Pós-Graduação em História, Niterói, $2007 . \quad$ Disponível em: <http://www.historia.uff.br/stricto/teses/Tese-2007_WITTER_Nikelen-S.pdf>. Acesso em: 12 maio 2014. 